\title{
Cloud Point Extraction for the Determination of Trace Amounts of Cobalt in Water and Food Samples by Flame Atomic Absorption Spectrometry
}

\author{
Shangzhi Wang, Shuangming Meng, and Yong Guo \\ College of Chemistry and Chemical Engineering, Shanxi Datong University, Datong 037009, China \\ Correspondence should be addressed to Shangzhi Wang; ws_spring@163.com
}

Received 29 June 2012; Accepted 11 September 2012

Academic Editor: Yuh-chang Sun

Copyright (C) 2013 Shangzhi Wang et al. This is an open access article distributed under the Creative Commons Attribution License, which permits unrestricted use, distribution, and reproduction in any medium, provided the original work is properly cited.

\begin{abstract}
A cloud point extraction (CPE) procedure which was developed for the separation and preconcentration of trace amounts of cobalt is combined with flame atomic absorption spectrometry (FAAS) to determine trace amounts of cobalt in water and food samples. The procedure is based on the formation of the hydrophobic complex between Co(II) and 4-methoxy-2-sulfobenzenediazoaminoazo-benzene (MOSDAA) followed by its extraction into a Triton X-114 surfactant-rich phase. The parameters such as $\mathrm{pH}$ of sample, concentrations of MOSDAA and Triton X-114, equilibrium temperature, and equilibrium time, which affect both complexation and extraction, are optimized. Under the selected optimum conditions, the preconcentration of $10.0 \mathrm{~mL}$, $0.1 \mu \mathrm{g} \mathrm{mL}^{-1} \mathrm{Co}(\mathrm{II})$ solution results in a limit of detection of $0.47 \mathrm{ng} \mathrm{mL}^{-1}(3 \sigma)$ and an enrichment factor of 19. A relative standard deviation of $2.78 \%\left(n=6, c=0.1 \mu \mathrm{g} \mathrm{mL}^{-1}\right)$ for the determination of $\mathrm{Co}$ (II) is obtained. The proposed method was applied for the determination of trace amounts of cobalt in river water and millet samples with satisfactory results.
\end{abstract}

\section{Introduction}

Cobalt is an essential trace element in human body. Being a component of vitamin B12 (cyanocobalamin), it plays an important role in the production of the blood red cells and the prevention of pernicious anemia [1]. It is known that the toxicity of Cobalt is quite low, but high exposure to this element can cause diseases such as asthma and skin irritation. Therefore, to determine trace amounts of cobalt becomes significantly important in the fields of environmental analysis, process control, and medicine $[2,3]$.

In the aspect of determining trace amounts of cobalt in different matrixes, many analytical techniques such as flame atomic absorption spectrometry (FAAS) [4], inductively coupled plasma mass spectrometry (ICP-MS) [5], inductively coupled plasma optical emission spectrometry (ICP-OES) [6] and graphite furnace atomic absorption spectrometry (GFAAS) [7] have been developed. Flame atomic absorption spectrometry (FAAS) has been considered as a relatively simple and precise technique which is widely used for the determination of trace metal ions. However, direct determination of cobalt ion at trace level by FAAS does not present the sensitivity requirements, and, more importantly, it is affected by matrix interference. Thus, preliminary separation and preconcentration of trace cobalt element from the matrix are frequently necessary to improve the detection limit and the selectivity. These factors make several procedures developed for the separation and preconcentration of cobalt, including coprecipitation [8], liquid-liquid extraction $[9,10]$, solid phase extraction [11, 12], and flotation [13].

Recently, cloud point extraction (CPE) has become an attractive area for the separation and preconcentration of trace metal ions [24-27]. The principles of CPE have been illustrated in some interesting reviews [28-30]. Nonionic surfactants in aqueous solutions tend to form micelles and become turbid at a certain temperature, which is called "cloud point temperature." Above the temperature, the micellar solution separates into two phases: a surfactant-rich phase of a small volume and a dilute aqueous phase [31]. When metal ions react with a suitable ligand and form an aqueous low 


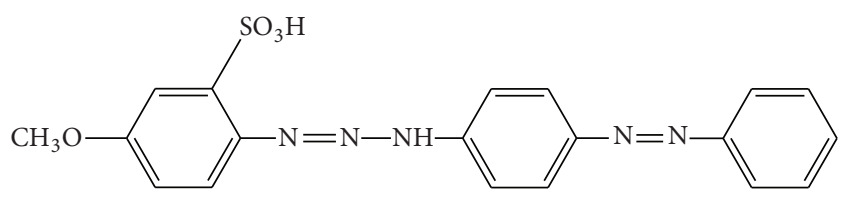

FIgURE 1: The structure of MOSDAA.

solubility complex, they can be extracted from the aqueous solution into the small-volume surfactant-rich phase. This method is simple experimental procedure with low cost, environmental safety, high capacity for preconcentration of wide variety of analytes, and high enrichment factor with good recoveries $[28,32,33]$. In view of these advantages, cloud point extraction and flame atomic absorption have been combined together to determine various metal ions in environmental samples [3,34-37]. Therefore, in the present paper, cloud point extraction will be used to preconcentrate trace cobalt, and flame atomic absorption spectrometry is used to determine trace cobalt in water and food samples.

\section{Experimental}

2.1. Reagents. All chemicals used in the work were of analytical reagent grade. Deionized water $(18.2 \mathrm{M} \Omega \cdot \mathrm{cm})$ was used in all experiments. $1.000 \mathrm{mg} \mathrm{mL}^{-1} \mathrm{Co}$ (II) ion standard solution was prepared by dissolving appropriate amount of nitrate salt of $\mathrm{Co}$ (II) ion. Working solutions were prepared by dilution of the stock solution with distilled deionized water. The nonionic surfactant Triton X-114 (Sigma, St. Loius, MO, USA) was used without further purification. A $5.0 \%(\mathrm{v} / \mathrm{v})$ Triton X-114 was prepared by dissolving $5.0 \mathrm{~mL}$ of Triton X114 in distilled water in $100 \mathrm{~mL}$ volumetric flask with stirring. A $0.02 \%$ MOSDAA (MOSDAA was synthesized according to the a procedure reported previously [38]; the structure of MOSDAA is presented in Figure 1.) solution was prepared by dissolving $0.0158 \mathrm{~g}$ of MOSDAA in $100 \mathrm{~mL}$ volumetric flask with stirring. A buffer solution of $\mathrm{pH} 9.0$ was prepared by using sodium tetraborate 10-hydrate (Beijing Chemical Works) and acid boric (Beijing Chemical Works) at 0.05 and $0.5 \mathrm{~mol} \mathrm{~L}^{-1}$ concentrations. The vessels and pipettes used for trace analysis were kept overnight in $10 \%(\mathrm{~m} / \mathrm{v})$ nitric acid (Reagent No.1 Factory Of Shanghai Chemical Reagent Co., Ltd.) solution and subsequently washed four times with deionized water.

2.2. Apparatus. A Shimadzu AA-6800 atomic absorption spectrometer equipped with a cobalt hollow cathode lamp (Beijing Shuguangming Electronic Lighting Instrument Co., Ltd.) and an air-acetylene flame atomizer; was used in all determinations. The instrumental parameters were adjusted according to the manufacturer's recommendations. The working conditions are as follows: wavelength $(240.7 \mathrm{~nm})$, lamp current $(4.0 \mathrm{~mA})$, spectral bandwidth $(0.2 \mathrm{~nm})$, height of observation $(5.0 \mathrm{~mm})$, flow rate of air $\left(6.0 \mathrm{~L} \mathrm{~min}^{-1}\right)$, and flow rate of acetylene $\left(1.6 \mathrm{~L} \mathrm{~min}^{-1}\right)$. An $80-2$ centrifuge (Jintan Ronghua Instrument Manufacture Co., Ltd.) was used to accelerate the phase-separation process. A pHS-3C pHmeter (Shanghai Dapu Instruments Co., Ltd.) furnished with a combined glass-saturated calomel electrode was used for $\mathrm{pH}$ measurements.

2.3. Procedure. A cloud point experiment has been carried out according to the following procedure. Aliquots of $15 \mathrm{~mL}$ of the working solution containing $\mathrm{Co}$ (II) ion $\left(2.0 \mu \mathrm{g} \mathrm{mL}^{-1}\right)$, $0.3 \mathrm{~mL}$ of Triton X-114 (5.0\% v/v), $1.0 \mathrm{~mL}$ of MOSDAA $(0.02 \%)$, and $1.5 \mathrm{~mL} \mathrm{pH} 9.0$ buffer solution were mixed and placed in a graduated centrifuge tube. The mixture was diluted to $15 \mathrm{~mL}$ by the secondary distilled water. Then, the solution was kept at $80^{\circ} \mathrm{C}$ for $20 \mathrm{~min}$ in the thermostatic bath for equilibration. The separation into two phases was accelerated by centrifugation for $5 \mathrm{~min}$ at $1500 \mathrm{rpm}$. The solution was then cooled in an ice bath for $10 \mathrm{~min}$ in order to increase the viscosity of the surfactant-rich phase and facilitate the removal of the aqueous phase. The remaining surfactant-rich phase (approximately $300 \mu \mathrm{L}$ ) was dissolved in $0.5 \mathrm{~mL}$ of $0.1 \mathrm{~mol} \mathrm{~L}^{-1} \mathrm{HNO}_{3}$ in order to reduce its viscosity. The Co(II) content was readily evaluated by FAAS.

2.4. Application. The real samples include water and millet samples. Water samples were taken from Shili river of Datong city. They were filtered into a clean flask. Millet samples $(2.50 \mathrm{~g})$ were porphyrized and dried. They were put into the dry beaker, and then $30.0 \mathrm{~mL}$ hydrogen peroxide was added. After $10 \mathrm{~h}$ of the reaction, the mixture was placed on the heating furnace to dissolve at a low temperature for about $3 \mathrm{~h}$. When the resultant solution was heated to dryness, $5.0 \mathrm{~mL}$ $\mathrm{HNO}_{3}$, was added. After the solution was dry again, proper amount of water was added. The solution was heated for a while, and then it was cooled at room temperature. The solution was diluted to $20 \mathrm{~mL}$. The blank solution was also prepared.

\section{Results and Discussion}

To achieve the best performance for the cloud point extraction procedure, the effects including $\mathrm{pH}$, concentrations of ligand and surfactant, temperature and time of equilibration on the analytical signal, dilution condition, centrifuge time and rates, and interfering ions were evaluated and optimized.

3.1. Effect of $p H$. The formation of metallic complex and its chemical stability are the two important factors involved in the separation and preconcentration of metal ions by cloud point extraction (CPE). They need to present sufficient hydrophobicity to be extracted into the small volume of the surfactant-rich phase. The $\mathrm{pH}$ plays a critical role on metallic complex formation and subsequent extraction and has been a significant parameter for CPE. Thus, extraction yield depends on the $\mathrm{pH}$ at which complex formation is investigated. A set of similar experiments was carried out in the $\mathrm{pH}$ range of 4.0-10.0. The solutions were buffered by mixtures of sodium tetraborate 10-hydrate and acid boric or acetic acid and sodium acetate. As it can be seen in Figure 2, in terms of these phenomena, $\mathrm{pH} 9.0$ (sodium tetraborate 10-hydrate and acid 


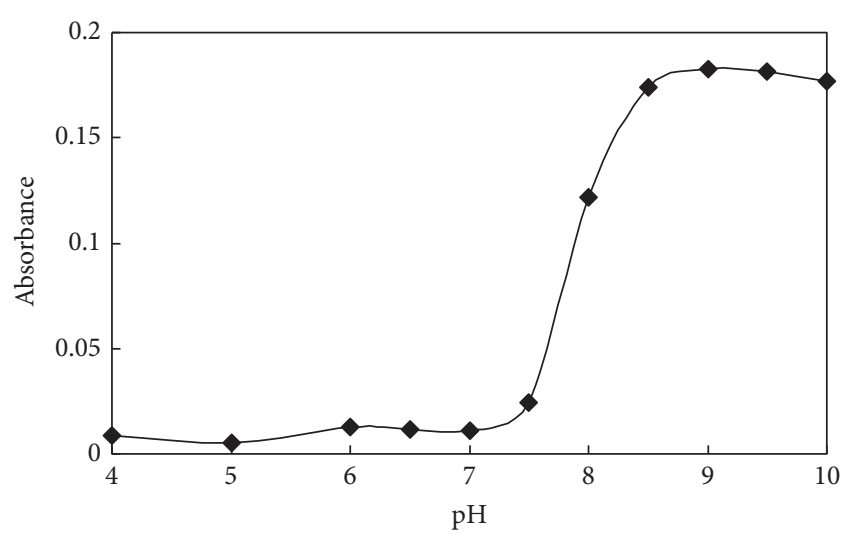

FIgURE 2: Effect of $\mathrm{pH}$ on the analytical signal of cobalt. Conditions: $2.0 \mu \mathrm{g} / \mathrm{mL} \mathrm{Co}(\mathrm{II})$ ion, $0.1 \%(\mathrm{v} / \mathrm{v})$ Triton $\mathrm{X}-114,1 \mathrm{~mL}$ of $0.02 \%$ MOSDAA.

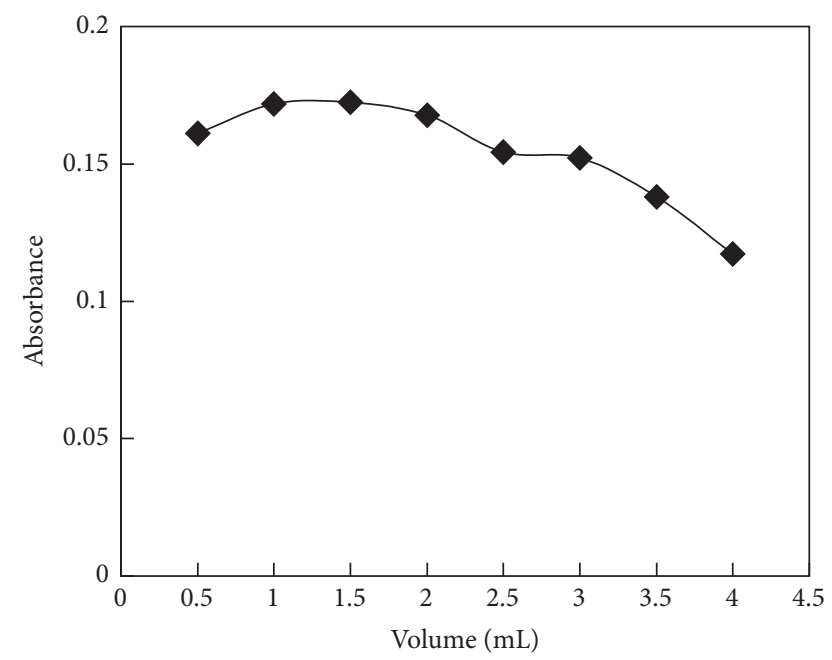

FIGURE 3: Effect of the amount of buffer solution on the absorbance of Co(II). Conditions: $2.0 \mu \mathrm{g} / \mathrm{mL} \mathrm{Co}(\mathrm{II})$ ion, $0.1 \%(\mathrm{v} / \mathrm{v})$ Triton X$114,1 \mathrm{~mL}$ of $0.02 \%$ MOSDAA, $\mathrm{pH} 9.0$, temperature: $80^{\circ} \mathrm{C}$.

boric, $0.05+0.5 \mathrm{~mol} \mathrm{~L}^{-1}$ ) was selected for the subsequent studies.

In addition, it is noted that the absorbance values are large and stable when the amount of buffer solution $(\mathrm{pH} 9.0)$ is in the range of 1.0-2.0 $\mathrm{mL}$ (see Figure 3). The largest absorbance value occurs when the amount of buffer solution $(\mathrm{pH} \mathrm{9.0)} \mathrm{is}$ $1.5 \mathrm{~mL}$, thus this amount is selected for the investigation.

3.2. Effect of the Amount of MOSDAA. After the formation of sparingly water-soluble complexes, the CPE is used for the preconcentration of metal ions. Its efficiency strongly depends on the hydrophobicity of the ligand and the complex formed in the miceller medium. Therefore, the effect of the amount of MOSDAA on the analytical responses was subsequently studied. Therefore, a set of similar experiments under the conditions of $2.0 \mu \mathrm{g} \mathrm{mL}^{-1} \mathrm{Co}(\mathrm{II})$ ion, $5.0 \%(\mathrm{v} / \mathrm{v})$ Triton X-114, pH 9.0 and various amounts of MOSDAA was carried out. The respective results are presented in Figure 4.

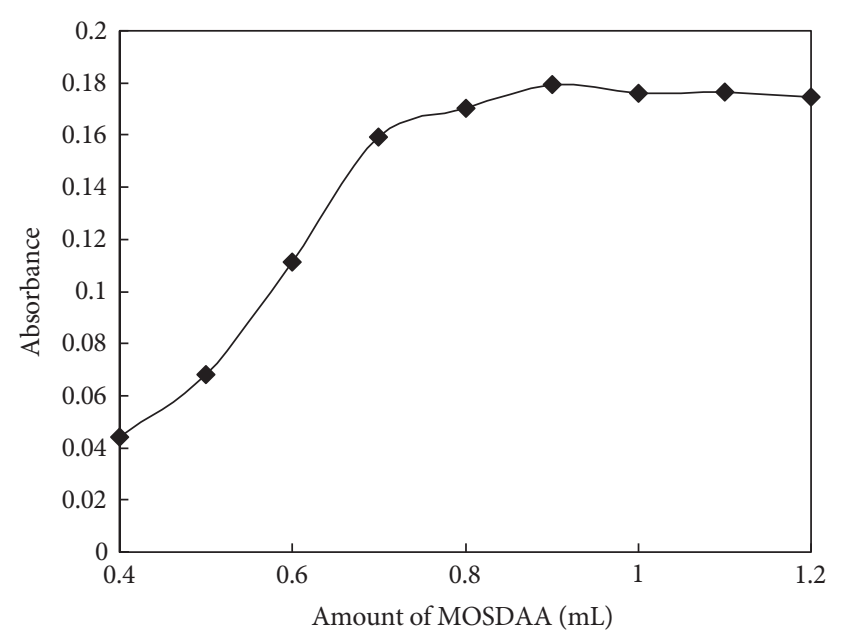

FIgURE 4: Effect of the amount of MOSDAA on the absorbance of Co(II). Conditions: $2.0 \mu \mathrm{g} / \mathrm{mL} \mathrm{Co}(\mathrm{II})$ ion, $0.1 \%$ (v/v) Triton X-114, pH 9.0, temperature: $80^{\circ} \mathrm{C}$.

It was found that the absorbance augments by increasing the ligand concentration. The sensitivity increases up to $0.9 \mathrm{~mL}$ of the amount of MOSDAA which reaches a plateau. At this amount, the extraction of $2.0 \mu \mathrm{g} \mathrm{mL}^{-1} \mathrm{Co}$ (II) ion can be considered completely. In view of the complicacy of the sample, a volume of $1.0 \mathrm{~mL}$ is selected as a suitable amount of MOSDAA for the extraction process in order to make the extraction reaction complete.

3.3. Effect of the Amount of Triton X-114. Triton X-114 is one of the nonionic surfactant extensively used in CPE [29] because it has the advantages such as commercial availability with high purity, low toxicity and cost, high density of the surfactant-rich phase facilitating the phase separation by centrifugation, and relatively low cloud point temperature $[39,40]$. Its concentration determines not only the result of extraction separation, but also the volume of the enriched micellar phase. Thus, the effect of the amount of Triton X-114 on cobalt extraction was evaluated by varying the surfactant amount in the range of $0.1-0.8 \mathrm{~mL}$. As it can be seen from Figure 5, Co absorbance reaches up to the largest when the surfactant amount increases up to $0.30 \mathrm{~mL}$ and the volume ratio is $0.02 \%(\mathrm{v} / \mathrm{v})$ (micelle to aqueous phase). Above this Triton X-114 amount, the analytical signal starts to decrease. This can be attributed to an increase in volume and viscosity of the surfactant phase. Thus, a volume of $0.30 \mathrm{~mL}$ Triton X114 was used for subsequent experiments.

3.4. Effects of Equilibration Temperature and Time. Two important factors in cloud point extraction are equilibration temperature and incubation time. It is known that when $\mathrm{CPE}$ is conducted using equilibration temperatures that are well above the cloud point temperature of the surfactant, the greatest analyte preconcentration factors will be obtained $[40,41]$. It is desirable to employ the shortest incubation time and the lowest incubation temperature in order to ensure the completion of extraction and efficient separation of phases. 


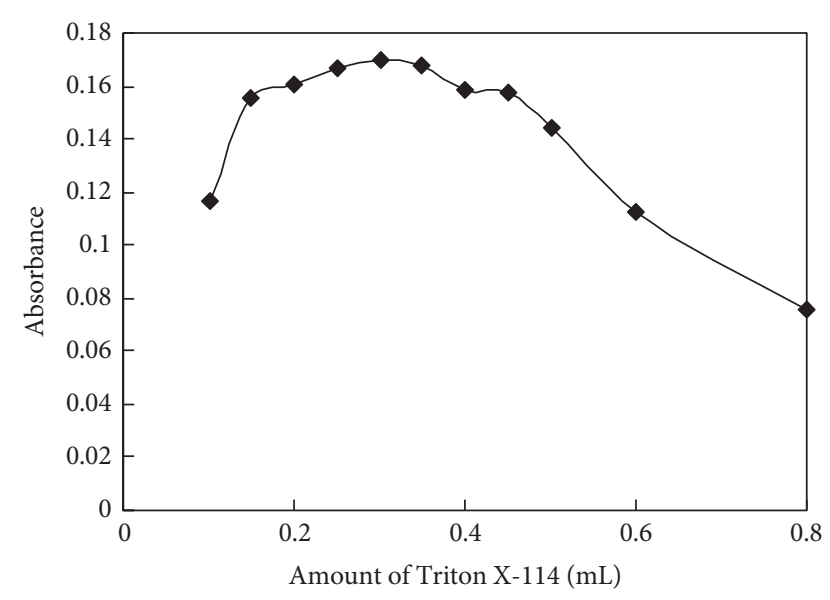

FIGURE 5: Effect of the amount of Triton X-114 on the absorbance of Co(II). Conditions: $2.0 \mu \mathrm{g} / \mathrm{mL} \mathrm{Co}(\mathrm{II})$ ion, $1 \mathrm{~mL}$ of $0.02 \%$ MOSDAA, pH 9.0, temperature: $80^{\circ} \mathrm{C}$.

Based on these reasons, the effect of equilibration temperature and time was examined. The dependence of extraction efficiency upon equilibration temperature and time above the cloud point in the range of $25-100^{\circ} \mathrm{C}$ and 5-60 min was thoroughly optimized, respectively (see Figures 6 and 7). The results showed that an equilibration temperature of $80^{\circ} \mathrm{C}$ and a time of $20 \mathrm{~min}$ were adequate to achieve quantitative extraction, and there were no appreciable improvements for a time longer than $20 \mathrm{~min}$. Therefore, an equilibration temperature of $80^{\circ} \mathrm{C}$ and an incubation time of $20 \mathrm{~min}$ were used.

3.5. Effect of Dilution Condition. It should be noted that after cloud point preconcentration, the surfactant-rich phase obtained becomes very viscous owing to the Triton X-114 that it contains. In order to facilitate the sample introduction in the FAAS nebulizer, it is necessary to decrease the viscosity of the surfactant-rich phase to facilitate the subsequent handling and introduction into the atomizer. So it is usually necessary for the addition of a diluting solution in the surfactant-rich phase to obtain a clear and homogenous solution of low viscosity compatible with the requirements of flame and plasma nebulizer. Hence, a solution of $0.1 \mathrm{~mol} \mathrm{~L}^{-1}$ $\mathrm{HNO}_{3}$ was selected as the diluting agent. Various amounts of $0.1 \mathrm{~mol} \mathrm{~L}^{-1} \mathrm{HNO}_{3}$ were added to decrease the viscosity of the surfactant-rich phase. The results indicate that the largest absorbance is obtained when $0.5 \mathrm{~mL}$ of $0.1 \mathrm{~mol} \mathrm{~L}^{-1} \mathrm{HNO}_{3}$ is added and then it was diluted to $2.0 \mathrm{~mL}$ by the secondary distilled water (see Figure 8). Finally, an optimal volume of $0.5 \mathrm{~mL} 0.1 \mathrm{~mol} \mathrm{~L}^{-1} \mathrm{HNO}_{3}$ was chosen in order to ensure good absorbance signal.

3.6. Effects of Centrifuge Time and Rates. It is very necessary to preconcentrate trace amounts of $\mathrm{Co}$ (II) ion with high efficiency in a short time. Therefore, on the basis of the optimum conditions so far obtained, the effect of the centrifuge time and rates was studied. The results suggest that centrifugation

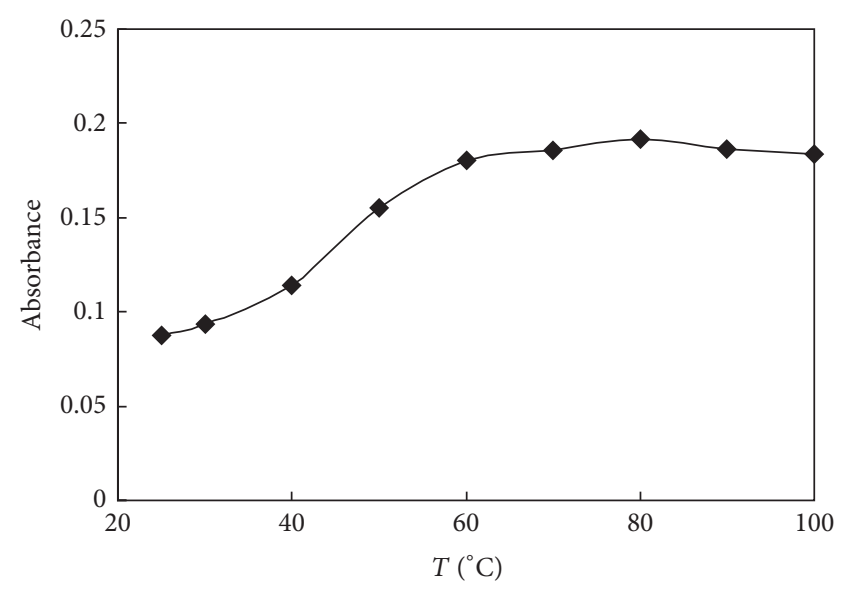

FIgURE 6: Effect of equilibration temperature on the absorbance of $\mathrm{Co}(\mathrm{II})$. Conditions: equilibration time of $20 \mathrm{~min}$, centrifugation for $5 \mathrm{~min}$ at $1500 \mathrm{rpm}$.

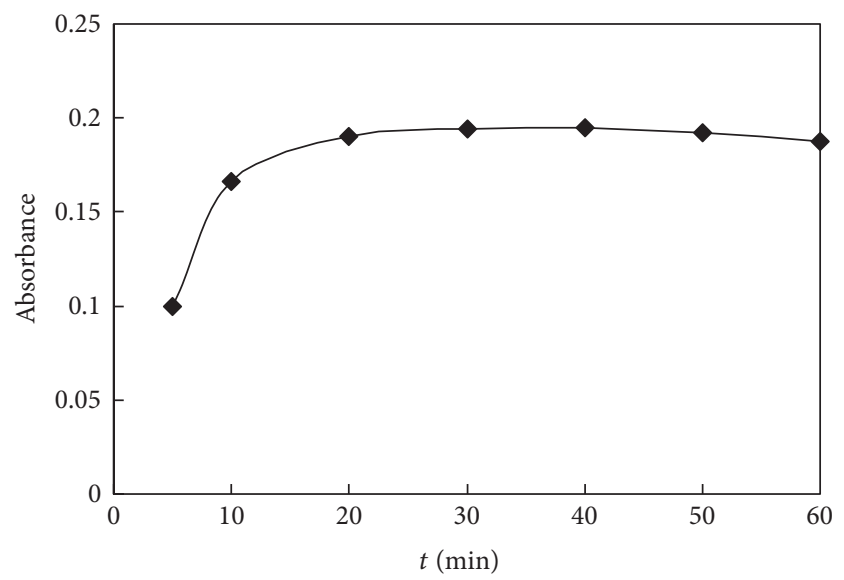

FIgURE 7: Effect of equilibration time on the absorbance of Co(II). Equilibration temperature of $80^{\circ} \mathrm{C}$, centrifugation for $5 \mathrm{~min}$ at $1500 \mathrm{rpm}$.

for $5 \mathrm{~min}$ at $1500 \mathrm{rpm}$ and cooling for $10 \mathrm{~min}$ in an ice-bath lead to the highest recovery and sensitivity for $\mathrm{Co}(\mathrm{II})$ ion.

3.7. Effect of Interference. The effects of foreign ions on the extraction of $2 \mathrm{ug} / \mathrm{mL} \mathrm{Co(II)} \mathrm{were} \mathrm{tested.} \mathrm{The} \mathrm{tolerated}$ amounts of each ion were the concentration values tested that caused error less than $\pm 5 \%$ of the recovery alteration. The tolerable concentration ratios of foreign ions within the ranges are summarized in Table 1. It is shown that the recovery is quantitative and satisfactory in the presence of a large amount of foreign metal ions such as $\mathrm{K}(\mathrm{I}), \mathrm{Na}(\mathrm{I})$, $\mathrm{Mg}(\mathrm{II}), \mathrm{Ca}(\mathrm{II})$, and these cations in the water and real samples have no obvious influence on CPE of $\mathrm{Co}$ (II) ion under the selected conditions. It can be observed that the tolerable concentration ratios of $\mathrm{Cu}(\mathrm{II}), \mathrm{Zn}(\mathrm{II})$, and $\mathrm{Fe}(\mathrm{III})$ are very low, their existences would significantly affect the CPE of $\mathrm{Co}(\mathrm{II})$ ion under the selected conditions. The reason may be that these cations can form complexes with MOSDAA, and this will make the complexation between $\mathrm{Co}(\mathrm{II})$ and 


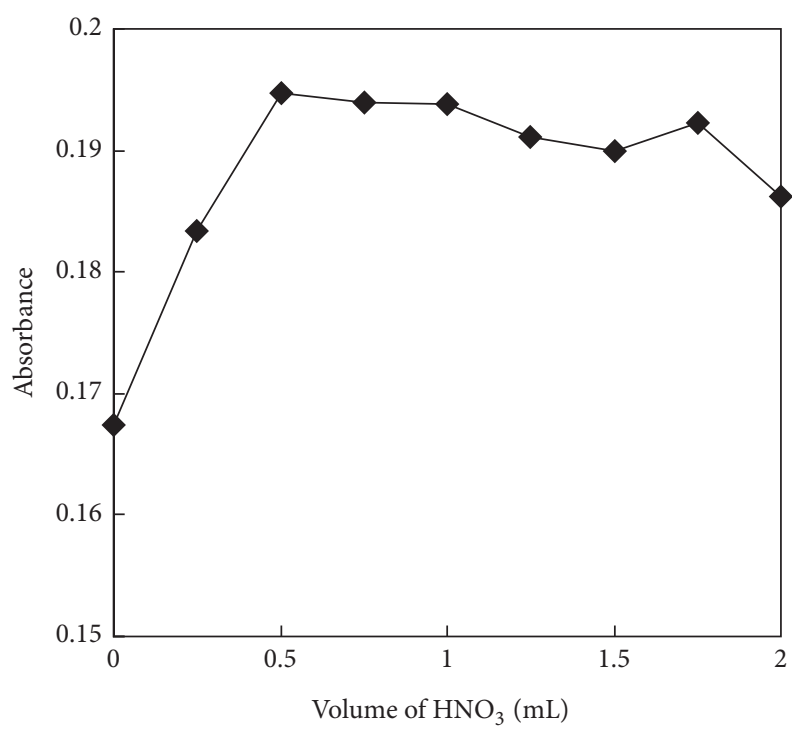

Figure 8: Effect of the amount of $\mathrm{HNO}_{3}$ on the absorbance of Co(II).

TABLE 1: Effects of the foreign ions on the recoveries of the Co(II) ion $(n=3)$.

\begin{tabular}{lcc}
\hline Interfering ions & $\begin{array}{c}\text { Interfering ion/analyte fold ratio } \\
(\mathrm{w} / \mathrm{w})\end{array}$ & Recovery/\% \\
\hline $\mathrm{K}(\mathrm{I})$ & 1000 & 101.4 \\
$\mathrm{Na}(\mathrm{I})$ & 1000 & 99.3 \\
$\mathrm{Mg}(\mathrm{II})$ & 1000 & 103.8 \\
$\mathrm{Ca}(\mathrm{II})$ & 1000 & 96.2 \\
$\mathrm{Mn}(\mathrm{II})$ & 200 & 98.7 \\
$\mathrm{~Pb}(\mathrm{II})$ & 200 & 100.6 \\
$\mathrm{Cu}(\mathrm{II})$ & 20 & 97.6 \\
$\mathrm{Zn}(\mathrm{II})$ & 20 & 95.6 \\
$\mathrm{Ba}(\mathrm{II})$ & 100 & 96.0 \\
$\mathrm{Ni}(\mathrm{II})$ & 100 & 95.2 \\
$\mathrm{Fe}(\mathrm{III})$ & 10 & 96.3 \\
\hline
\end{tabular}

MOSDAA less efficient. Therefore, to eliminate these effects, more amounts of MOSDAA are supposed to be added.

3.8. Characteristics of the Method. A calibration curve of absorbance versus concentration was constructed by collecting the analytical signals of different volumes of Co(II) standard solutions submitted to the method proposed. Under the optimum experimental conditions, the calibration curve for $\mathrm{Co}(\mathrm{II})$ ion is linear from 0.002 to $1.2 \mu \mathrm{g} / \mathrm{mL}$ with a correlation coefficient $(R)$ of 0.9984 . Table 2 gives the parameters of the calibration curve, enrichment factor, the relative standard deviation obtained for 6 replicates subjected to the complete procedure and the detection limit. The enrichment factor as the ratio of Co concentration of the analyte after preconcentration to that before preconcentration is 19 . The relative
TABLE 2: Characteristics performance of the presented CPE method.

\begin{tabular}{lc}
\hline Parameter & Optimum value \\
\hline Equation for the calibration curve, & $A=0.0767 C_{\mathrm{Co}}+0.0095$ \\
$C /\left(\mu \mathrm{g} \mathrm{mL}^{-1}\right)$ & 0.9984 \\
Correlation coefficient $(R)$ & $0.002-1.2$ \\
Linear range $\left(\mu \mathrm{g} \mathrm{mL}^{-1}\right)$ & 2.78 \\
$\mathrm{RSD}(\%, n=6)$ & 0.47 \\
Limit of detection $\left(\mathrm{ng} \mathrm{mL}^{-1}\right)$ & 19 \\
$\left(3 S_{b} / m, n=11\right)$ & $\sim 1$ \\
Enrichment factor & 0.02 \\
Extraction coefficient & \\
Phase volume ratio &
\end{tabular}

Enrichment factor: ratio between Co concentration in the surfactant-rich phase and in the original solution.

Extraction coefficient: ratio between Co quantity in the surfactant-rich phase after the cloud point and in the original solution.

Phase volume ratio: ratio between the final volume of the surfactant-rich phase and the aqueous phase.

TABLE 3: Determination of cobalt in water and millet samples $(n=$ $3)$.

\begin{tabular}{lccc}
\hline Sample & Added $/ \mu \mathrm{g} \mathrm{g}^{-1}$ & ${ }^{*}$ Found value $/ \mu \mathrm{g} \mathrm{g}^{-1}$ & Recovery $/ \%$ \\
\hline \multirow{4}{*}{ Millet } & 0 & $0.07 \pm 0.02$ & \\
& 0.05 & $0.12 \pm 0.02$ & 100.0 \\
& 0.1 & $0.17 \pm 0.03$ & 100.0 \\
\multirow{4}{*}{ River water } & 0.1 & $1.05 \pm 0.03$ & 98.0 \\
& 0.2 & $0.20 \pm 0.05$ & \\
& 1.0 & $0.30 \pm 0.05$ & 100.0 \\
${ }^{*} \bar{X} \pm\left(t_{p, t} s / \sqrt{n}\right), P=0.95, f=2$. & $0.39 \pm 0.04$ & 95.0 \\
& 0 & $1.16 \pm 0.10$ & 96.0 \\
\hline
\end{tabular}

standard deviation (RSD) for 6 replicate measurements of $100 \mathrm{ng} \mathrm{mL}^{-1} \mathrm{Co}(\mathrm{II})$ ion was $2.78 \%$. The limit of detection defined as $3 \mathrm{Sb} / \mathrm{m}$ (where $\mathrm{Sb}$ is the standard deviation of the blank and $\mathrm{m}$ is the slope of the calibration curve) is $0.47 \mathrm{ng} \mathrm{mL}^{-1}(3 \sigma)$.

A comparison of the represented method with other reported cloud point extraction methods is given in Table 4. As seen from the table, the detection limit for method is comparable to those given by many methods in the table. In addition, enrichment factor can be improved by using larger sample volumes.

3.9. Analysis of Real Samples. In order to validate the methodology, the proposed method was applied to the determination of $\mathrm{Co}(\mathrm{II})$ ion concentration in water and millet samples. The accuracy was checked by spiking the samples with different concentrations of $\mathrm{Co}(\mathrm{II})$ ion. The results are shown in Table 3. It shows that recoveries are greater than $96 \%$, and indicating that the proposed method is suitable for the sample types examined. Thus, the method proposed can be considered reliable for $\mathrm{Co}$ (II) determination in a wide range of samples. 
TABLE 4: Procedure using cloud point extraction prior to cobalt determination by FAAS.

\begin{tabular}{|c|c|c|c|c|c|}
\hline Reagent & Surfactant & Sample volume $/ \mathrm{mL}$ & $\mathrm{EF}^{\mathrm{a}}$ & $\mathrm{LOD}^{\mathrm{b}} /\left(\mu \mathrm{g} \mathrm{L}^{-1}\right)$ & Reference \\
\hline Ammonium pyrrolidine dithiocarbamate & Triton X-114 & 10 & 20 & 5 & {$[14]$} \\
\hline 1-(2-Thiazolylazo)-2-naphthol & Triton X-114 & 50 & 57 & 0.24 & {$[15]$} \\
\hline 1-(2-Pyridylazo)-2-naphthol & Triton X-114 & 10 & 115 & 0.38 & {$[16]$} \\
\hline 2-(5-Bromo-2-pyridylazo)-5-diethylaminophenol & Triton X-100 & 12.5 & 28.5 & 1.06 & {$[17]$} \\
\hline 1-nitroso-2-naphthol & PONPE 7.5 & 10 & 27 & 1.22 & {$[18]$} \\
\hline 2-[2'-(6-Methyl-benzothiazolylazo)]-4-bromophenol & Triton X-114 & 10 & 28 & 0.9 & [19] \\
\hline Methyl-2-pyridylketone oxime & Triton X-114 & 15 & 67 & 2.1 & {$[20]$} \\
\hline 2-[(2-Mercaptophenylimino)methl]phenol & Triton X-114 & 25 & 97 & 0.21 & {$[21]$} \\
\hline 2-guanidinobenzimidazole & Triton X-114 & 50 & 13 & 7.8 & {$[22]$} \\
\hline 1-Phenylthiosemicarbazide & Triton X-114 & 50 & 25 & 1 & {$[23]$} \\
\hline 4-Methoxy-2-sulfo-benzenediazoaminoazo-benzene & Triton X-114 & 15 & 19 & 0.47 & This work \\
\hline
\end{tabular}

${ }^{\mathrm{a}}$ Enhancement factor, ${ }^{\mathrm{b}}$ limit of detection.

\section{Conclusions}

Cloud point extraction is a simple, inexpensive, sensitive, and rapid method in preconcentration and separation of trace metal. TritonX-114 is used as cloud point extractant because it has the low cloud point temperature and high density, and, more importantly, it is very cheap. In the $\mathrm{pH} 9.0$ buffer system of sodium tetraborate 10-hydrate and acid boric, $\mathrm{Co}$ (II) and MOSDAA can form stable complexation. After extraction preconcentration by neutral surface active agents Triton $\mathrm{X}$ 114 , the element Co can be measured to the level of $\mathrm{ng} \mathrm{mL}^{-1}$, which is very satisfactory.

\section{References}

[1] H. G. Seiler and A. Siegel, Handbook on Metals in Clinical Analytical Chemistry, Marcel Dekker, New York, NY, USA, 1994.

[2] Q. Zhang, H. Minami, S. Inoue, and I. Atsuya, "Determination of ultra-trace amounts of cobalt in seawater by graphite furnace atomic absorption spectrometry after pre-concentration with Ni/8-quinolinol/1-nitroso-2-naphthol complex," Analytica Chimica Acta, vol. 407, no. 1-2, pp. 147-153, 2000.

[3] N. Baghban, A. M. H. Shabani, S. Dadfarnia, and A. A. Jafari, "Flame atomic absorption spectrometric determination of trace amounts of cobalt after cloud point extraction as 2-[(2mercaptophenylimino)methyl]phenol complex," Journal of the Brazilian Chemical Society, vol. 20, no. 5, pp. 832-838, 2009.

[4] M. M. M. El-Defrawy, J. Posta, and M. T. Beck, "Elimination of the interfering effects of ligands in the determination of cobalt by atomic absorption spectrometry," Analytica Chimica Acta, vol. 115, pp. 155-161, 1980.

[5] E. Bárány, I. A. Bergdahl, L. E. Bratteby et al., "Trace element levels in whole blood and serum from Swedish adolescents," Science of the Total Environment, vol. 286, no. 1-3, pp. 129-141, 2002.

[6] K. S. Rao, T. Balaji, T. P. Rao, Y. Babu, and G. R. K. Naidu, "Determination of iron, cobalt, nickel, manganese, zinc, copper, cadmium and lead in human hair by inductively coupled plasma-atomic emission spectrometry," Spectrochimica Acta B, vol. 57, no. 8, pp. 1333-1338, 2002.
[7] A. S. Ribeiro, M. A. Vieira, A. F. Da Silva et al., "Determination of cobalt in biological samples by line-source and highresolution continuum source graphite furnace atomic absorption spectrometry using solid sampling or alkaline treatment," Spectrochimica Acta B, vol. 60, no. 5, pp. 693-698, 2005.

[8] A. Tong, Y. Akama, and S. Tanaka, "Pre-concentration of copper, cobalt and nickel with 3-methyl-1-phenyl-4-stearoyl5-pyrazolone loaded on silica gel," Analyst, vol. 115, no. 7, pp. 947-949, 1990.

[9] A. Gupta and S. M. Khopkar, "Solvent extraction separation of cobalt(II) with hexaacetatocalix(6)arene," Talanta, vol. 42, no. 10, pp. 1493-1496, 1995.

[10] H. Eskandari, H. S. Ghaziaskar, and A. A. Ensafi, "A sensitive and simple extractive-spectrophotometric method for the determination of microgram amount of cobalt by using $\alpha$-benzilmonoxime," Analytical Sciences, vol. 17, no. 2, pp. 327-331, 2001.

[11] J. L. Manzoori, M. H. Sorouradin, and A. M. H. Shabani, "Atomic absorption determination of cobalt after preconcentration by 1-(2-pyridylazo)-2-naphthol immobilized on surfactant-coated alumina," Microchemical Journal, vol. 63, no. 2, pp. 295-301, 1999.

[12] S. Cadore, R. D. Goi, and N. Baccan, "Flame atomic absorption determination of cobalt in water after extraction of its morpholinedithiocarbamate complex," Journal of the Brazilian Chemical Society, vol. 16, no. 5, pp. 957-962, 2005.

[13] K. Čundeva, T. Stafilov, and G. Pavlovska, "Flotation separation of cobalt and copper from fresh waters and their determination by electrothermal atomic absorption spectrometry," Microchemical Journal, vol. 65, no. 2, pp. 165-175, 2000.

[14] D. L. Giokas, E. K. Paleologos, S. M. Tzouwara-Karayanni, and M. I. Karayannis, "Single-sample cloud point determination of iron, cobalt and nickel by flow injection analysis flame atomic absorption spectrometry-application to real samples and certified reference materials," Journal of Analytical Atomic Spectrometry, vol. 16, no. 5, pp. 521-526, 2001.

[15] J. Chen and K. C. Teo, "Determination of cobalt and nickel in water samples by flame atomic absorption spectrometry after cloud point extraction," Analytica Chimica Acta, vol. 434, no. 2, pp. 325-330, 2001.

[16] J. L. Manzoori and G. Karim-Nezhad, "Sensitive and simple cloud-point preconcentration atomic absorption spectrometry: application to the determination of cobalt in urine samples," Analytical Sciences, vol. 19, no. 4, pp. 579-583, 2003. 
[17] C. C. Nascentes and M. A. Z. Arruda, "Cloud point formation based on mixed micelles in the presence of electrolytes for cobalt extraction and preconcentration," Talanta, vol. 61, no. 6 , pp. 759-768, 2003.

[18] J. L. Manzoori and A. Bavili-Tabrizi, "Cloud point preconcentration and flame atomic absorption spectrometric determination of cobalt and nickel in water samples," Mikrochimica Acta, vol. 141, no. 3-4, pp. 201-207, 2003.

[19] V. A. Lemos, R. S. da França, and B. O. Moreira, "Cloud point extraction for $\mathrm{Co}$ and $\mathrm{Ni}$ determination in water samples by flame atomic absorption spectrometry," Separation and Purification Technology, vol. 54, no. 3, pp. 349-354, 2007.

[20] M. Ghaedi, A. Shokrollahi, F. Ahmadi, H. R. Rajabi, and M. Soylak, "Cloud point extraction for the determination of copper, nickel and cobalt ions in environmental samples by flame atomic absorption spectrometry," Journal of Hazardous Materials, vol. 150, no. 3, pp. 533-540, 2008.

[21] N. Baghban, A. M. H. Shabani, S. Dadfarnia, and A. A. Jafari, "Flame atomic absorption spectrometric determination of trace amounts of cobalt after cloud point extraction as 2-[(2mercaptophenylimino)methyl]phenol complex," Journal of the Brazilian Chemical Society, vol. 20, no. 5, pp. 832-838, 2009.

[22] N. Dallali, M. M. Zahedi, and Y. Yamini, "Simultaneous cloud point extraction and determination of $\mathrm{Zn}, \mathrm{Co}, \mathrm{Ni}$ and $\mathrm{Pb}$ by flame atomic absorption spectrometry, using 2guanidinobenzimidazole as the complexing agent," Scientia Iranica, vol. 14, no. 4, pp. 291-296, 2007.

[23] D. Citak and M. Tuzen, "A novel preconcentration procedure using cloud point extraction for determination of lead, cobalt and copper in water and food samples using flame atomic absorption spectrometry," Food and Chemical Toxicology, vol. 48, no. 5, pp. 1399-1404, 2010.

[24] V. A. Lemos, P. X. Baliza, and J. S. Santos, "Me-BTABr reagent in cloud point extraction for spectrometric determination of copper in water samples," Journal of the Brazilian Chemical Society, vol. 17, no. 1, pp. 30-35, 2006.

[25] A. Afkhami, T. Madrakian, and H. Siampour, "Cloud point extraction spectrophotometric determination of trace quantities of bismuth in urine," Journal of the Brazilian Chemical Society, vol. 17, no. 4, pp. 797-802, 2006.

[26] Y. Surme, I. Narin, M. Soylak, H. Yuruk, and M. Dogan, "Cloud point extraction procedure for flame atomic absorption spectrometric determination of lead(II) in sediment and water samples," Microchimica Acta, vol. 157, no. 3-4, pp. 193-199, 2007.

[27] M. F. Giné, A. F. Patreze, E. L. Silva, J. E. S. Sarkis, and M. H. Kakazu, "Sequential cloud point extraction of trace elements from biological samples and determination by inductively coupled plasma mass spectrometry," Journal of the Brazilian Chemical Society, vol. 19, no. 3, pp. 471-477, 2008.

[28] M. de Almeida Bezerra, M. A. Zezzi Arruda, and S. L. C. Ferreira, "Cloud point extraction as a procedure of separation and pre-concentration for metal determination using spectroanalytical techniques: a review," Applied Spectroscopy Reviews, vol. 40, no. 4, pp. 269-299, 2005.

[29] E. K. Paleologos, D. L. Giokas, and M. I. Karayannis, "Micellemediated separation and cloud-point extraction," Trends in Analytical Chemistry, vol. 24, no. 5, pp. 426-436, 2005.

[30] M. F. Silva, E. S. Cerutti, and L. D. Martinez, "Coupling cloud point extraction to instrumental detection systems for metal analysis," Microchimica Acta, vol. 155, no. 3-4, pp. 349-364, 2006.
[31] M. J. Rosen, Surfactants and Interfacial Phenomena, Wiley Interscience, New York, NY, USA, 1987.

[32] W. L. Hinze and E. Pramauro, "A Critical review of surfactantmediated phase separations (cloud-point extractions). Theory and applications," Critical Reviews in Analytical Chemistry, vol. 24, no. 2, pp. 133-177, 1993.

[33] A. Sanz-Medel, M. D. R. Fernandez De La Campa, E. B. Gonzalez, and M. L. Fernandez-Sanchez, "Organized surfactant assemblies in analytical atomic spectrometry," Spectrochimica Acta B, vol. 54, no. 2, pp. 251-287, 1999.

[34] A. Shokrollahi, M. Ghaedi, O. Hossaini, N. Khanjari, and M. Soylak, "Cloud point extraction and flame atomic absorption spectrometry combination for copper(II) ion in environmental and biological samples," Journal of Hazardous Materials, vol. 160, no. 2-3, pp. 435-440, 2008.

[35] M. Ghaedi, A. Shokrollahi, K. Niknam, E. Niknam, A. Najibi, and M. Soylak, "Cloud point extraction and flame atomic absorption spectrometric determination of cadmium(II), lead(II), palladium(II) and silver(I) in environmental samples," Journal of Hazardous Materials, vol. 168, no. 2-3, pp. 10221027, 2009.

[36] S. A. M. Fathi and M. R. Yaftian, "Cloud point extraction and flame atomic absorption spectrometry determination of trace amounts of copper(II) ions in water samples," Journal of Colloid and Interface Science, vol. 334, no. 2, pp. 167-170, 2009.

[37] M. Ghaedi, A. Shokrollahi, R. Mehrnoosh, O. Hossaini, and M. Soylak, "Combination of cloud point extraction and flame atomic absorption spectrometry for preconcentration and determination of trace iron in environmental and biological samples," Central European Journal of Chemistry, vol. 6, no. 3, pp. 488-496, 2008.

[38] L. Xu, Z. Y. Hu, Y. W. Liu, S. M. Meng, and J. L. Wang, "Synthesis of 4-methoxy-2-sulfo-benzenediazoaminoazobenzene(MOSDAA) and its colour reaction with mercury(III)," Chinese Journal of Spectroscopy Laboratory, vol. 25, no. 3, pp. 319-322, 2008.

[39] M. E. F. Laespada, J. L. P. Pavón, and B. M. Cordero, "Micellemediated methodology for the preconcentration of uranium prior to its determination by flow injection," The Analyst, vol. 118, no. 2, pp. 209-212, 1993.

[40] R. P. Frankewich and W. L. Hinze, "Evaluation and optimization of the factors affecting nonionic surfactant-mediated phase separations," Analytical Chemistry, vol. 66, no. 7, pp. 944-954, 1994.

[41] A. Safavi, H. Abdollahi, M. R. H. Nezhad, and R. Kamali, "Cloud point extraction, preconcentration and simultaneous spectrophotometric determination of nickel and cobalt in water samples," Spectrochimica Acta A, vol. 60, no. 12, pp. 2897-2901, 2004. 

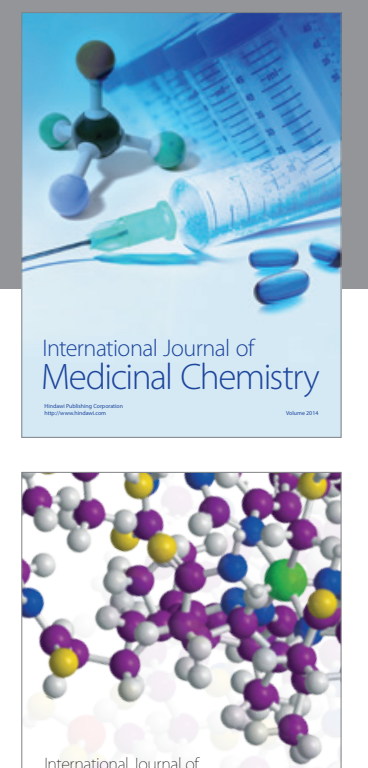

\section{Carbohydrate} Chemistry

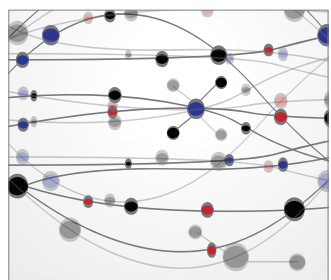

The Scientific World Journal
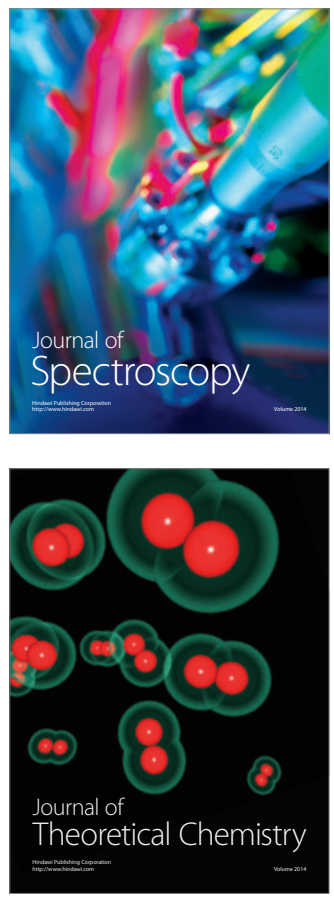
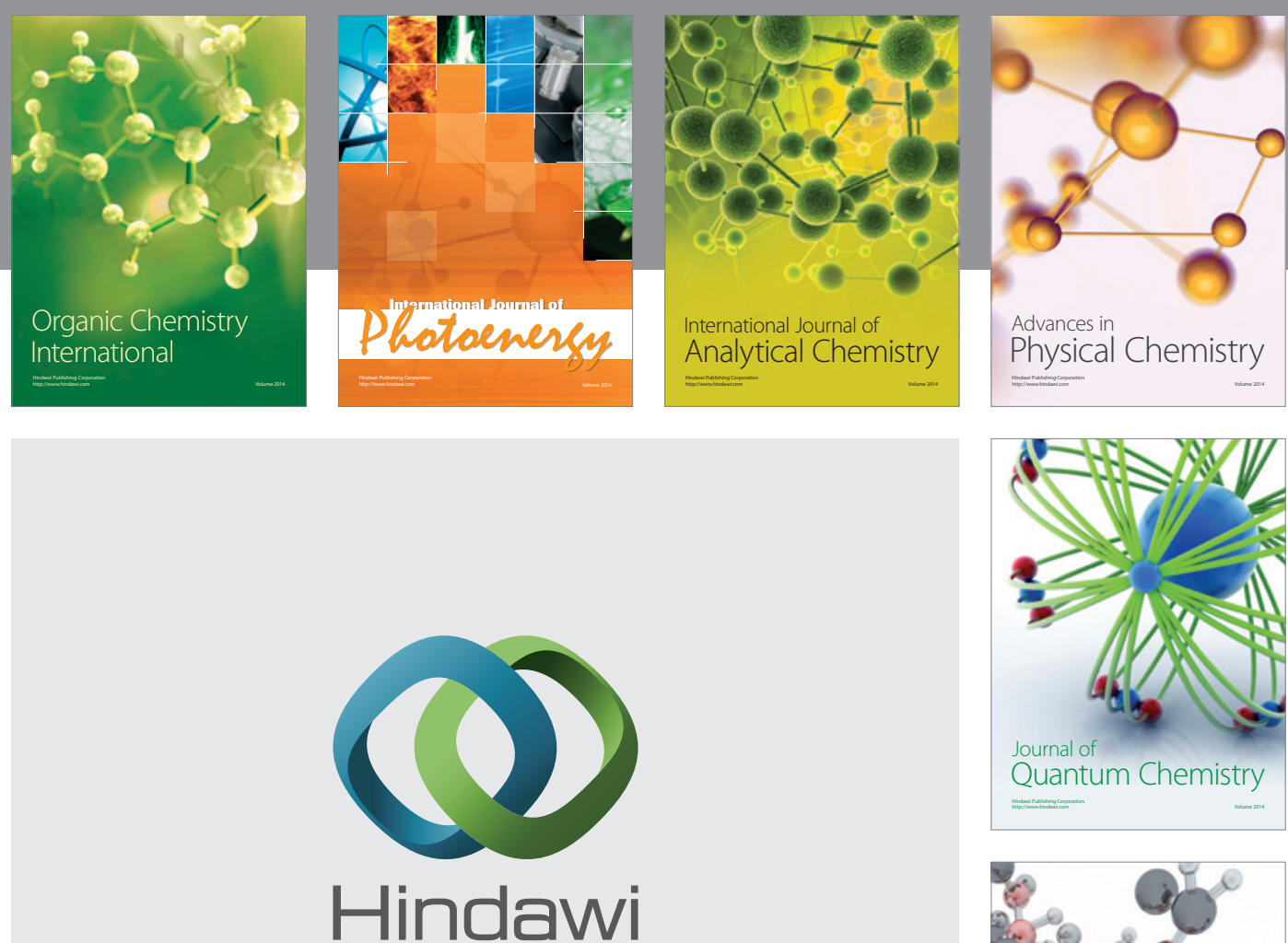

Submit your manuscripts at

http://www.hindawi.com

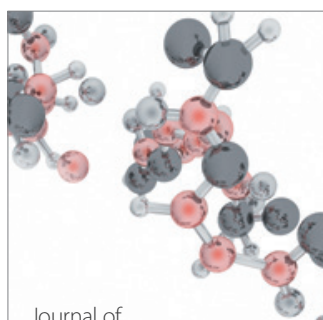

Analytical Methods

in Chemistry

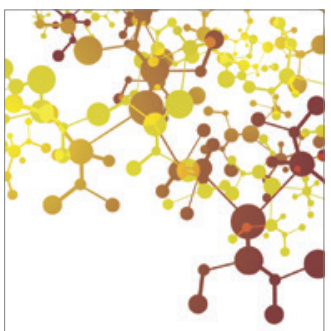

Journal of

Applied Chemistry

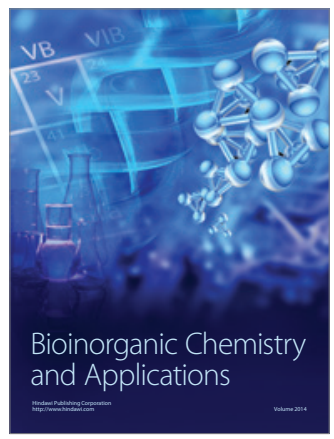

Inorganic Chemistry
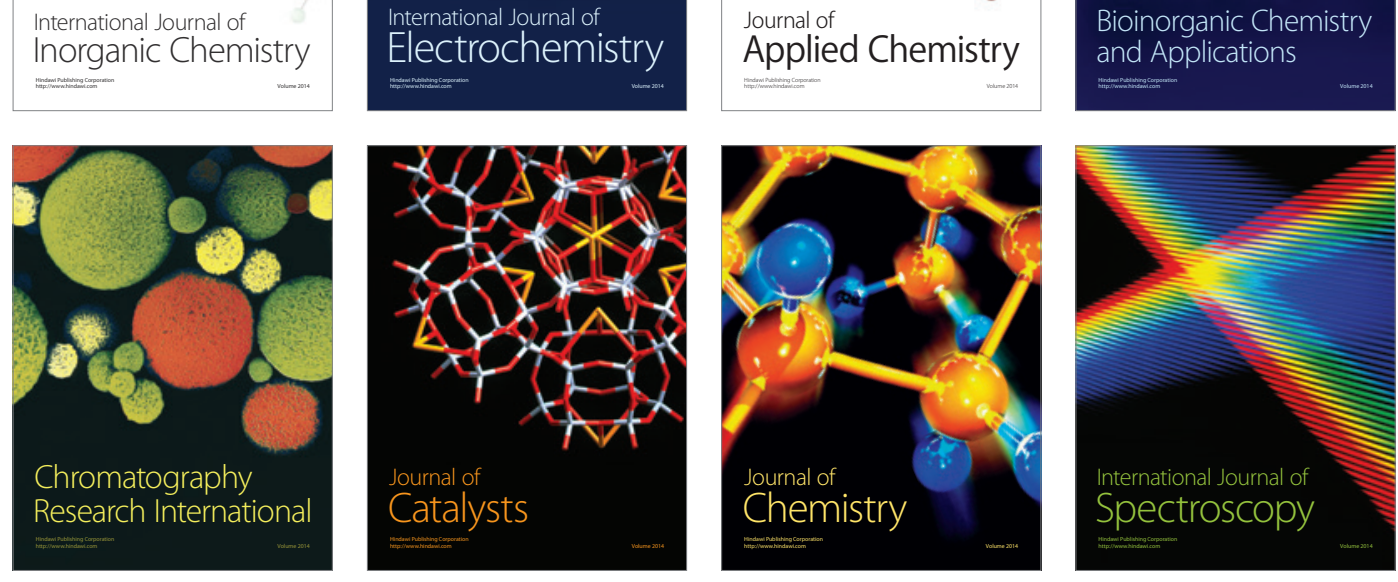